Portland State University

PDXScholar

\title{
Racial and Ethnic Disparities in Desire for Reversal of Sterilization among U.S. Women
}

\author{
Ginny Garcia-Alexander \\ Portland State University, ginny.garciaalexander@pdx.edu \\ Kelly Gonzales \\ Portland State University \\ Elizabeth Carol Hauck \\ Portland State University
}

Follow this and additional works at: https://pdxscholar.library.pdx.edu/soc_fac

Part of the Sociology Commons, and the Women's Health Commons

Let us know how access to this document benefits you.

\section{Citation Details}

Garcia, Ginny; Gonzales, Kelly; and Hauck, Liz, "Racial and Ethnic Disparities in Desire for Reversal of Sterilization Among U.S. Women," Population Association of America Annual Meeting, Washington, DC, April 2016,

This Working Paper is brought to you for free and open access. It has been accepted for inclusion in Sociology Faculty Publications and Presentations by an authorized administrator of PDXScholar. Please contact us if we can make this document more accessible: pdxscholar@pdx.edu. 
WORKING PAPER

\title{
Racial and Ethnic Disparities in Desire for Reversal of Sterilization among U.S. Women
}

\begin{abstract}
Purpose: Female sterilization rates and subsequent desire for reversal of the procedure are substantially higher in minorities, low-income women, and those who use public insurance. Despite the disproportionate distribution of these outcomes, few studies in this area have considered the extent to which such disparities are attributable to a restricted set of contraceptive options among medically underserved populations, which may in turn explain higher rates of desire for reversal.

Methods: We use the most recent wave of NSFG data (2011-2013) to estimate odds ratios for race/ethnicity on the likelihood of desire for reversal of sterilization, while controlling for an array of factors that have been shown to negate or lessen the racial/ethnic association including age at sterilization, primary reason for sterilization, and insurance coverage, among others. Results: Outcomes indicate much higher odds of desire for reversal of sterilization among black and Latina women, despite the inclusion of a range of controls. Additionally, we find that rates are much higher in women who reported "single service or no insurance coverage" as well as those who cited "some other reason" (versus completion of desired childbearing) as the main reason for their sterilization.

Conclusions: These findings are noteworthy and suggest that disadvantage seems to play an important role in desire for reversal of sterilization. Additional research in this area is needed in inform efforts to improve care and enhance the reproductive autonomy of medically underserved women.
\end{abstract}

Keywords: sterilization, sterilization reversal, racial/ethnic disparities, reproductive decisionmaking 


\section{WORKING PAPER}

\section{Introduction}

Tubal sterilization is regarded as one of the safest and most effective methods of birth control in the U.S. (ACOG 2012). In fact, it ranks as the second leading method of birth control in American women (Mosher \& Jones 2010). However, prior studies have revealed significant variations in sterilization rates on the basis of factors including: race/ethnicity, level of education, and method of payment or insurance coverage. Specifically, it is observed that black and Latina/Hispanic women, those with lower levels of education, and those who utilize public insurance (Medicaid) are far more likely to undergo sterilization (ACOG 2012; Borerro et al. 2011; Chan and Westhoff 2010; MacKay et al. 2001); a pattern which has remained stable over many decades (Mosher \& Jones 2010). Unfortunately, a sizeable proportion of those who undergo sterilization later go on to report desire for reversal of sterilization procedure. In fact, recent estimates indicate that approximately one-quarter of women desire reversal of their sterilization procedure (Borrero et al. 2008).

Variations in regret and/or desire for reversal on the basis of several factors are welldocumented. For example, a systematic review of the literature revealed that these outcomes decreased for those who underwent the procedure at older ages (Curtis, Mohllajee \& Peterson 2006). Accordingly, women who underwent the procedure at 25 years of age or younger have been shown to have much higher levels of subsequent desire for reversal (Curtis et al. 2006). However, age does not fully account for variations in this outcome, which has been shown to be higher in black women, those who were unmarried at the time of procedure, and those who use public insurance (Borrero et al. 2008; Hillis et al. 1999). A study of long-term regret also revealed higher rates in those who had the sterilization procedure post-partum (Hillis et al. 1999); a time which is identified as ideal by the American College of Obstetricians and 


\section{WORKING PAPER}

Gynecologists (ACOG) and during which the vast majority of sterilizations are performed (2012).

Though the exact reasons for persistent racial/ethnic variations in sterilizations remain unclear, some have suggested that culturally distinct patient preference drives observed differences (Borrero et al. 2011; Potter et al. 2012). On the other hand, it has been shown that low-income black and Latina women are more often advised to limit childbearing (Downing et al. 2007) or to have been counseled on sterilization (Dehlendorf et al. 2010). In fact, several studies have revealed that minority women are more likely to perceive pressure to engage in family planning or adopt a method of contraception (Becker and Tsui 2008; Yee \& Simon 2011). Still, others posit that racial/ethnic differences in desire for reversal are removed or lessened significantly after controlling for age at sterilization (Borerro et al. 2008).

Interestingly, much of the research in this area highlights barriers to access in postpartum sterilization and laments the number of unintended pregnancies that could have been avoided if women were afforded greater access to the procedure (Borrero et al. 2014). Indeed, a growing body of research has called for greater access to this procedure and suggests that Medicaidpolicy barriers ${ }^{1}$ act to prevent access to desired sterilization. Some have gone so far as to suggest that the 30-day waiting period required by Medicaid for those who wish to undergo postpartum sterilization is "ethically impermissible" and must be removed (Moaddab et al. 2015: 736). However, such calls may be premature given our lack of understanding of the role of various factors in producing disparate reproductive health outcomes. Warranting additional concern is the historical legacy of racism and coercive practices in sterilizations that prompted the

\footnotetext{
${ }^{1}$ Regulations to govern federally funded sterilization procedures were enacted in 1979 following evidence of widespread coercive sterilizations of minorities and low-income women, among others (Sollom, Gold, \& Saul 1996). The regulations included informed and written consent 30 days in advance of the procedure and prohibited sterilization of those under age 21 or considered mentally incompetent.
} 


\section{WORKING PAPER}

enactment of federal protections to ensure such practices were prevented in the first place. Given the growing body of research documenting differential practices in the health care setting and their connection to health disparities (Smedley, Stith, and Nelson 2002), a great deal of caution must be exercised in addressing the reproductive health needs of vulnerable populations.

Surprisingly little attention has been given to the disparate nature of sterilization procedures and/or desire for reversal; a pattern which may be driven by disadvantage, and translates into a marked lack of alternatives in reproductive decision-making. Some scholars have argued for the re-framing of this issue with attention to the lack of choices available to certain sub-groups (Bass \& Warehime; Garcia et al. 2015). This restricted choice framework highlights the lack of autonomy afforded to medically underserved women (minorities and those who use public insurance) in reproductive decision-making and contraception. Such arguments are based on the fact that women who don't otherwise have insurance coverage become eligible for public insurance during pregnancy. However, pregnancy-based coverage only extends to the 60-day period following the birth. As such, women may choose to undergo a permanent method of contraception, i.e. sterilization, while coverage is in effect as opposed to foregoing or choosing a method that requires ongoing maintenance or follow-up care.

Thus, the present study uses the most recent wave of the National Survey of Family Growth (NSFG 2011-2013) to provide additional evidence in support of this argument. Formally, we: 1) examine the extent to which racial and ethnic disparities are present in desire for reversal after accounting for the influence of factors including age at sterilization and other sociodemographic characteristics; and 2) examine the influence of insurance coverage and primary motivation for sterilization on subsequent desire for reversal. While we do not have a direct measure of the insurance used for the sterilization procedure, we do include a measure of the 


\section{WORKING PAPER}

respondent's current insurance status/coverage. Our measure of the primary motivation for receipt of sterilization accounts for those who underwent the procedure for medical reasons or because they completed desired childbearing, as opposed to some other reason. We hypothesize that desire for reversal of sterilization will be higher in racial and ethnic minorities as well as those who report a lack of coverage or use of public insurance; and lower in those who underwent sterilization at a later age or upon completion of desired childbearing.

\section{Data and Methods}

To conduct our analysis, we use the National Survey of Family Growth (NSFG) 20112013. The NSFG is a multi-stage probability based, nationally representative sample of the household population aged 15-44 (2013). The 2011-2013 data provides information on 5,601 women; teens, blacks, and Hispanics are oversampled. Only those women who underwent sterilization and provided a valid response to the primary reason for sterilization are included to produce an analytic sample of 331. Logistic regressions were used to test hypotheses and assess the likelihood of desire for reversal of sterilization procedure. All analyses were weighted to permit nationally representative estimates of the female household population aged 15-44 (Lepowski et al. 2013). Analyses were performed using STATA 13.0.

Our dependent variable is based on responses to the question, "If your tubal sterilization could be reversed safely, would you want to have it reversed?" Responses included definitely yes, probably yes, probably no, or definitely no. These were recoded into a dichotomous variable with those women who reported definitely or probably yes coded as 1 and those who reported definitely or probably no as 0 . Our primary independent variable is race/ethnicity, and includes non-Hispanic white, non-Hispanic black, and Hispanic (other was excluded due to insufficient sample size and lack of variation in outcome). To capture the respondent's insurance coverage, 


\section{WORKING PAPER}

we utilize a measure of the current insurance. Categories include private insurance (reference), Medicaid/CHIP/state-sponsored care, and single-service/Indian Health Service/no insurance coverage. Additionally, we include a variable which reflects the woman's primary reason for sterilization: medical reasons (reference), desired childbearing completed, "some other reason", and no answer.

We further control for the effects of a number of known covariates. These include age at sterilization (in years); parity (dichotomous: $0=0-2$ children; $1=3$ or more children); and marital status $(0=$ not married, $1=$ married $)$. Urban/rural status is based on census designations for metropolitan statistical areas (MSA). Categories include principle city of MSA (reference), other MSA/suburban, and non-MSA. Finally, level of education is operationalized with the categories: less than high school (reference), high school, some college, and associate's degree or higher.

\section{Results}

Table 1 presents summary statistics for women who have undergone sterilization. The data suggest that a sizeable proportion of all women desire reversal of their sterilization procedure $(26.86 \%)$, but these rates are a great deal higher in black and Latina women (36.08 and $45.55 \%$, respectively) ( $\mathrm{p} \leq .05)$. Significant differences were also observed on the basis of insurance coverage such that those reporting current Medicaid coverage or single-service only/no coverage had far higher rates of desire for reversal than those currently covered by private insurance $(35.63 \%, 41.03 \%$, and $18.51 \%$, respectively). Similarly, substantial variations in the outcome were observed on the basis of primary reason for sterilization. Thus, $59.14 \%$ of women who underwent the procedure for "some other reason" desired reversal, while only $18.43 \%$ of those who completed desired childbearing reported desire for reversal. The average age at 


\section{WORKING PAPER}

sterilization across all the women in the sample was 29.50. Among those who did not desire reversal the average age was 30.38 years; in women who desired reversal the average age was 27.35 years $(\mathrm{p} \leq .05)$. Interestingly, those who had three or more children had higher rates than those with fewer children ( $32.81 \%$ vs. $20.09 \%$; $\leq \leq .05)$. Rates were also higher in unmarried women, and those in the lower categories of education. Finally, those in non-MSA's (rural areas) had relatively lower levels of desire for reversal than those in urban areas, while nearly one-third $(31.43 \%)$ of those in suburban areas desired reversal.

Table 2 presents the results of logistic regression analyses. Our results are presented as odds ratios. Here, it is observed that the odds of desire for reversal of sterilization procedure are 6.38 times higher for black women and 2.47 times higher for Latinas, all else equal. These differences remain despite the inclusion of a range of controls. Insurance coverage also exerted a significant effect. Formally, those who currently reported single-service only or no coverage had 2.99 higher odds of desire for reversal than those with private insurance. Current coverage with Medicaid exerted a marginally significant positive effect on the outcome. Additionally, the primary reason for the procedure had a significant impact on likelihood of desire for reversal with those reporting "medical" and "some other reason" evidencing much higher odds of desire for reversal than those who reported having the procedure upon completion of desired childbearing. Notably, after controlling for other factors, those who reported "some other reason" had fourteen times higher odds than those who completed desired childbearing. Other significant predictors in the model included parity, education, and metropolitan status. Thus, women with 3 or more children had odds nearly four times those with fewer children of desiring a reversal, all else equal. Those in suburban areas (versus urban) and those with some college education also had elevated odds of desire for reversal. Age at sterilization and marital status did not exert a 


\section{WORKING PAPER}

significant influence on the outcome, though the effect for age at sterilization was approaching significance $(\mathrm{p}=0.08)$.

\section{Discussion}

A growing body of literature has begun to call for removal of the protections set up to protect the rights of vulnerable populations. These studies have argued that the paperwork and 30-day waiting period required prior to sterilization (for those covered by Medicaid) represents an undue burden that prevents access to desired procedures and generates unmet need for sterilization (ACOG 2012; Borrero et al. 2013; Potter et al. 2012; Zite, Wuellner, \& Gilliam 2006). Several studies have gone on to argue that much of the racial and ethnic variation observed in both rates of sterilization and subsequent desire for reversal is removed after the inclusion of such factors as age at sterilization procedure, parity, and/or number of past unintended pregnancies. However, a substantial body of literature has documented the presence of racial/ethnic disparities in reproductive health outcomes, the source of which remains poorly understood.

To shed further light on this issue, we examined the extent to which racial and ethnic disparities are present in desire for sterilization reversal, after controlling for an array of factors. We additionally considered the effect of current insurance coverage and the primary reason for sterilization on subsequent desire for reversal. Consistent with our initial hypothesis, the findings indicate highly disparate outcomes on the basis of race and ethnicity such that black women are six times and Latinas are nearly three times more likely to desire a reversal of their sterilization procedure. Such findings remained robust despite the inclusion of controls for various factors.

Our hypotheses were also supported in reference to insurance coverage and primary reason for sterilization. With the former, it was observed that those in the single-service only or 


\section{WORKING PAPER}

no coverage category experienced greater odds of desire for reversal. Because these surveys asked about past sterilizations, it is likely these women utilized public insurance to cover their sterilization procedure, and thus gives credence to the argument that disadvantaged women are overrepresented in rates of sterilization and subsequent desire for reversal. Additionally, current Medicaid coverage was approaching significance. With reference to the primary reason for sterilization, it was notable that the response of "some other reason" was associated with remarkably high odds of desire for reversal. While our measure was limited in its ability to clearly assess what "some other reason" meant with complete certainty, we were able to account for those who had the procedure for medical reasons or because they completed desired childbearing. It is thus arguable that physician influence may be reflected within this group. In light of growing evidence of the influence of physician recommendations on reproductive decision-making, taken together with findings of differential reproductive advice on the basis of race/ethnicity, level of education and method of payment, this finding is worthy of additional study and generates some concern as to its effects on the decision-making process. Finally, our finding of significantly higher odds of desire for reversal among those with more children was unexpected. However, it has been argued that providers are more likely to recommend sterilization to those with higher numbers of children (Borrero et al. 2008), which may account for this outcome.

As mentioned above, the present study was limited in its ability to reliably account for the extent of physician influence on recommendations for sterilization and later regret. However, the inclusion of a measure of the patient's primary reason for sterilization represents an improvement over previous studies. Future studies should incorporate measures that clearly differentiate between those who elected to have the procedure as a result of physician 


\section{WORKING PAPER}

recommendation or advice, and examine the extent to which pressure to undergo or utilize permanent contraception was experienced. We were further limited by the availability of reliable information on method of payment for sterilization, though we were able to incorporate a measure of current insurance. Additionally, we were unable to include system-level factors (hospital affiliation and size, operating room availability, etc.). Such factors have been shown to produce disparities in sterilization and other health outcomes. Future work should incorporate multi-level analysis to adequately account for the effects of individual and system-level factors. Finally, the NSFG only asked women whose procedure was performed in the past five years or less for information on their desire for reversal. Given the finding that regret increases over time, future studies should include all women who underwent the procedure, regardless of time elapsed. These limitations notwithstanding, our study is strengthened by the inclusion of ethnicity (Hispanic/Latina) in addition to race, the use of a nationally representative sample, and comprehensive measures of personal factors shown to influence sterilization outcomes.

Disproportionately high rates of sterilization procedures in minorities and those who use public insurance women may indeed be a reflection of greater need and/or desire for the procedure. However, robust findings of desire for reversal of the procedure among minorities and those with a lack of coverage may be an indication that certain sub-groups of women are subject to a limited set of choices that place undue influence on reproductive decision-making. Overall, these findings add to the large body of evidence documenting persistent racial and ethnic disparities in reproductive health outcomes. They further illustrate the need to continue to work toward identifying the source of such disparities. Taken together, our findings merit increased attention to the possibility of a limited set of choices in reproductive decision-making among underserved women. Further, additional studies are needed to determine the extent to 


\section{WORKING PAPER}

which institutional mechanisms and/or physician influence may contribute to disproportionately high rates of sterilization and desire for reversal in medically underserved women. 


\section{WORKING PAPER}

\section{References}

American College of Obstetricians and Gynecologists (ACOG), Committee on Health Care for Underserved Women. 2012. "Committee Opinion No. 530: Access to Postpartum Sterilization." Obstetrics \& Gynecology 120(1):212-15.

Bass, Loretta E, and M Nicole Warehime. 2009. "Do Health Insurance and Residence Pattern the Likelihood of Tubal Sterilization among American Women?" Population Research and Policy Review 28(2):237-49.

Becker, Davida, and Amy O Tsui. 2008. "Reproductive Health Service Preferences And Perceptions of Quality Among Low-Income Women: Racial, Ethnic and Language Group Differences." Perspectives on Sexual and Reproductive Health 40(4):202-11.

Borrero, Sonya, Nikki Zite, Joseph E Potter, and James Trussell. 2014. "Medicaid Policy on Sterilization-Anachronistic or Still Relevant?" New England Journal of Medicine 370(2):102-04.

Borrero, Sonya, Nikki Zite, Joseph E Potter, and James Trussell, and Kenneth Smith. 2013. "Potential Unintended Pregnancies Averted and Cost Savings Associated with a Revised Medicaid Sterilization Policy." Contraception 88(6): 691-696.

Borrero, Sonya, Kaleab Abebe, Christine Dehlendorf, Eleanor Bimla Schwarz, Mitchell D Creinin, Cara Nikolajski, and Said Ibrahim. 2011. "Racial Variation in Tubal Sterilization Rates: Role of Patient-Level Factors." Fertility and Sterility 95(1):17-22.

Borrero, Sonya B., Matthew F. Reeves, Eleanor B. Schwarz, James E. Bost, Mitchell D. Creinin, and Said A. Ibrahim. 2008. "Race, Insurance Status, and Desire for Tubal Sterilization Reversal." Fertility and Sterility 90(2):272-77.

Chan, Lolita M., and Carolyn L. Westhoff. 2010. "Tubal sterilization trends in the United States." Fertility and Sterility 94(1):1-6.

Curtis, Kathryn M, Anshu P Mohllajee, and Herbert B Peterson. 2006. "Regret Following Female Sterilization at a Young Age: A Systematic Review." Contraception 73(2):205-10.

Dehlendorf, Christine, Maria Isabel Rodriguez, Kira Levy, Sonya Borrero, and Jody Steinauer. 2010. "Disparities in Family Planning." American Journal of Obstetrics and Gynecology 202(3):214-20.

Downing, Roberta A., Thomas A. LaVeist, and Heather E. Bullock. 2007. "Intersections of Ethnicity and Social Class in Provider Advice Regarding Reproductive Health." American Journal of Public Health 97(10):1803-07. 


\section{WORKING PAPER}

Garcia, Ginny, Dawn M. Richardson, Kelly L. Gonzales, and Adolfo G. Cuevas. 2015. "Trends and Disparities in Postpartum Sterilization after Cesarean Section, 2000 through 2008." Women's Health Issues 25(6): 634-640.

Hillis, Susan D., Polly A. Marchbanks, Lisa Ratliff Tylor, and Herbert B. Peterson. 1999. "Poststerilization Regret: Findings from the United States Collaborative Review of Sterilization." Obstetrics \& Gynecology 93(6):889-95. Retrieved April 22, 2014 (http://journals.lww.com/greenjournal/Fulltext/1999/06000/Poststerilization_Regret_Finding s_From_the_United.1.aspx).

Lepowski, James M. , William D. Mosher, Robert M. Groves, Brady T. West, James Wagner, and Haley Gu. 2013. "Responsive Design, Weighting, and Variance Estimation in the 20062010 National Survey of Family Growth." Vital Statistics Series 2(158). Hyattsville, MD: National Center for Health Statistics.

Moaddab, Amirhossein, Laurence B McCullough, Frank A Chervenak, Karin A Fox, Kjersti Marie Aagaard, Bahram Salmanian, Susan P Raine, and Alireza A Shamshirsaz. 2015. "Health Care Justice and Its Implications for Current Policy of a Mandatory Waiting Period for Elective Tubal Sterilization." American Journal of Obstetrics and Gynecology 212(6):73639.

Mosher, William D, and Jo Jones. 2010. "Use of Contraception in the United States: 1982-2008." Vital and Health Statistics, Series 23, Data from the National Survey of Family Growth 29:144.

NSFG. 2016. "National Survey of Family Growth, 2011-2013." Hyattsville, MD: Division of Vital Statistics, National Center for Health Statistics.

Potter, Joseph E., Kari White, Kristine Hopkins, Sarah McKinnon, Michele G. Shedlin, Jon Amastae, and Daniel Grossman. 2012. "Frustrated Demand for Sterilization among LowIncome Latinas in El Paso, Texas." Perspectives on Sexual and Reproductive Health 44(4):228-35.

Smedley, Brian D, Adrienne Y Stith, and Alan R Nelson (Eds.). 2002. Unequal Treatment: Confronting Racial and Ethnic Disparities in Health Care: National Academies Press.

Sollom, Terry, Rachel Benson Gold, and Rebekah Saul. 1996. "Public Funding for Contraceptive, Sterilization and Abortion services, 1994." Family Planning Perspectives:16673.

Yee, L.M. , and M. A. Simon. 2011. "Perceptions of Coercion, Discrimination and Other Negative Experiences in Postpartum Contraceptive Counseling for Low-Income Minority Women." Journal of Health Care for the Poor and Underserved 22(4):1387-400. 


\section{WORKING PAPER}

Zite, Nikki, Sara Wuellner, and Melissa Gilliam. 2006. "Barriers to Obtaining a Desired Postpartum Tubal Sterilization." Contraception 73(4):404-7. 
WORKING PAPER

Table 1. Selected Characteristics of Women who Desire Reversal of Sterilization

\begin{tabular}{|c|c|c|c|}
\hline \multirow[b]{2}{*}{ Characteristic } & \multirow[b]{2}{*}{$\mathbf{N}$} & \multicolumn{2}{|c|}{ Does Not Desire } \\
\hline & & Reversal & Desires Reversal \\
\hline & & $\%$ (weighted) & $\%$ (weighted) \\
\hline All & 331 & 73.14 & 26.86 \\
\hline \multicolumn{4}{|l|}{ Race } \\
\hline NH White & 157 & 79.95 & $20.05^{*}$ \\
\hline Hispanic & 117 & 63.92 & $36.08 *$ \\
\hline NH Black & 57 & 54.45 & $45.55^{*}$ \\
\hline \multicolumn{4}{|l|}{ Current Insurance Coverage } \\
\hline Private & 148 & 82.63 & $17.37^{*}$ \\
\hline Medicaid & 68 & 64.37 & $35.63 *$ \\
\hline Single Svc Only/None & 112 & 59.40 & $40.60 *$ \\
\hline \multicolumn{4}{|l|}{ Reason for Sterilization } \\
\hline Completed Childbearing & 104 & 81.57 & $18.43^{*}$ \\
\hline Medical & 35 & 49.59 & $50.41 *$ \\
\hline Some Other Reason & 15 & 40.86 & $59.14 *$ \\
\hline No Answer & 177 & 71.57 & $28.43^{*}$ \\
\hline $\begin{array}{l}\text { Age at Sterilization (mean, } \\
\text { SD) }\end{array}$ & $29.50,5.35$ & $30.63,5.31$ & $27.35,4.82^{*}$ \\
\hline \multicolumn{4}{|l|}{ Parity } \\
\hline 0-2 children & 87 & 84.14 & $15.86^{*}$ \\
\hline 3 or more children & 244 & 67.70 & $32.30 *$ \\
\hline \multicolumn{4}{|l|}{ Marital Status } \\
\hline Married & 244 & 74.91 & 25.09 \\
\hline Unmarried & 87 & 61.04 & 38.96 \\
\hline \multicolumn{4}{|l|}{ Education } \\
\hline Less than HS & 78 & 67.84 & 32.16 \\
\hline High School & 113 & 65.55 & 34.45 \\
\hline Some College & 64 & 68.32 & 31.68 \\
\hline Assoc. + & 76 & 84.77 & 15.23 \\
\hline \multicolumn{4}{|l|}{ Metro Status } \\
\hline Principle MSA & 112 & 74.82 & 25.18 \\
\hline Suburban & 144 & 67.23 & 32.77 \\
\hline Non-MSA & 75 & 81.82 & 18.18 \\
\hline
\end{tabular}




\section{WORKING PAPER}

Table 2. Logistic Regression of Desire for Reversal of Sterilization, NSFG, 2011-2013 ( $n=345$ )

\begin{tabular}{|c|c|c|c|}
\hline Characteristic & Odds Ratio & & $95 \% \mathrm{Cl}$ \\
\hline Race & & & \\
\hline White (reference & & & \\
\hline Black & 6.382 & $* *$ & $1.937,21.031$ \\
\hline Latina & 2.487 & $*$ & $1.002,6.130$ \\
\hline Current Insurance & & & \\
\hline Private (ref) & & & \\
\hline Medicaid & 2.677 & & $0.803,8.930$ \\
\hline Single Svc/None & 2.987 & $*$ & $1.001,9.289$ \\
\hline Primary Reason & & & \\
\hline Comp. Childbeari & & & \\
\hline Medical & 6.069 & $* *$ & $1.977,18.629$ \\
\hline Other & 14.013 & $* *$ & $2.682,73.217$ \\
\hline No Answer & 1.990 & & $0.736,5.378$ \\
\hline Age at Sterilization & 0.934 & & $0.865,1.009$ \\
\hline Parity & & & \\
\hline 0-2 children (ref) & & & \\
\hline $3+$ children & 3.573 & $*$ & $1.209,10.557$ \\
\hline Marital Status & & & \\
\hline Unmarried (ref) & & & \\
\hline Married & 0.879 & & $0.312,2.477$ \\
\hline Education & & & \\
\hline Less than HS (ref) & & & \\
\hline High School & 1.760 & & $0.522,5.934$ \\
\hline Some College & 3.089 & $*$ & $1.000,9.559$ \\
\hline Assoc. + & 1.860 & & $0.407,8.508$ \\
\hline Metro Status & & & \\
\hline Principle MSA (re & & & \\
\hline Suburban & 2.731 & $*$ & $1.007,7.406$ \\
\hline Non-MSA & 0.741 & & $0.245,2.242$ \\
\hline Constant & 0.064 & & $0.002,1.844$ \\
\hline
\end{tabular}

